\title{
Commentary: Pleomorphic carcinoma: An aggressive type of non-small cell lung cancer that should be treated like the others
}

\author{
Natalie S. Lui, MD, MAS
}

\footnotetext{
From the Division of Thoracic Surgery, Department of Cardiothoracic Surgery, Stanford University, Stanford, Calif.

Disclosures: Author has nothing to disclose with regard to commercial support.

Received for publication April 23, 2019; accepted for publication April 23, 2019; available ahead of print June 10, 2019.

Address for reprints: Natalie S. Lui, MD, MAS, Division of Thoracic Surgery, Department of Cardiothoracic Surgery, Stanford University, 300 Pasteur Dr, Falk Building, Stanford, CA 94305 (E-mail: natalielui@stanford. edu).

J Thorac Cardiovasc Surg 2019;158:592-3

$0022-5223 / \$ 36.00$

Copyright (c) 2019 by The American Association for Thoracic Surgery

https://doi.org/10.1016/j.jtcvs.2019.04.074
}

Hendriksen and colleagues ${ }^{1}$ used the National Cancer Database (NCDB) to describe the largest published cohort of patients with pleomorphic lung carcinoma, a rare and aggressive type of non-small cell lung cancer (NSCLC). Pleomorphic carcinoma is 1 of the 5 subtypes of sarcomatoid carcinoma in the World Health Organization classification of lung tumors, and it is defined as a poorly differentiated NSCLC that contains at least $10 \%$ spindle or giant cells. ${ }^{2}$ There have been no clinical trials studying this disease, and the literature includes only retrospective institutional experience ${ }^{3,4}$ or national database studies $^{5,6}$ that frequently group together all subtypes of sarcomatoid carcinomas.

Hendriksen and colleagues ${ }^{1}$ took advantage of the fact that the NCDB is the largest cancer registry in the world. ${ }^{7}$ They confirm that pleomorphic carcinoma is indeed rare and aggressive: Pleomorphic carcinoma accounted for $0.1 \%$ of all cases of NSCLC, or 1408 patients from 2004 to 2015. Compared with patients with adenocarcinoma, patients with pleomorphic carcinoma were diagnosed at higher stages using the seventh edition of the American Joint Committee on Cancer Cancer Staging Manual. After propensity score matching, patients with pleomorphic carcinoma had worse 5-year overall survival for every stage (eg, $49.4 \%$ vs $59.1 \%$ for patients with stage I disease).

The National Comprehensive Cancer Network guidelines recommend considering adjuvant chemotherapy for patients with at least stage IB disease and high-risk factors such as poorly differentiated tumors, which by definition includes pleomorphic carcinoma. ${ }^{8}$ Multivariable time-toevent analysis showed that among patients with stage I pleomorphic carcinoma, there was no difference in 5-year overall survival between patients treated with surgery alone versus surgery with chemotherapy $(55.2 \%$ vs $53.7 \%$; $P=.29)$. Wedge resection was associated with worse

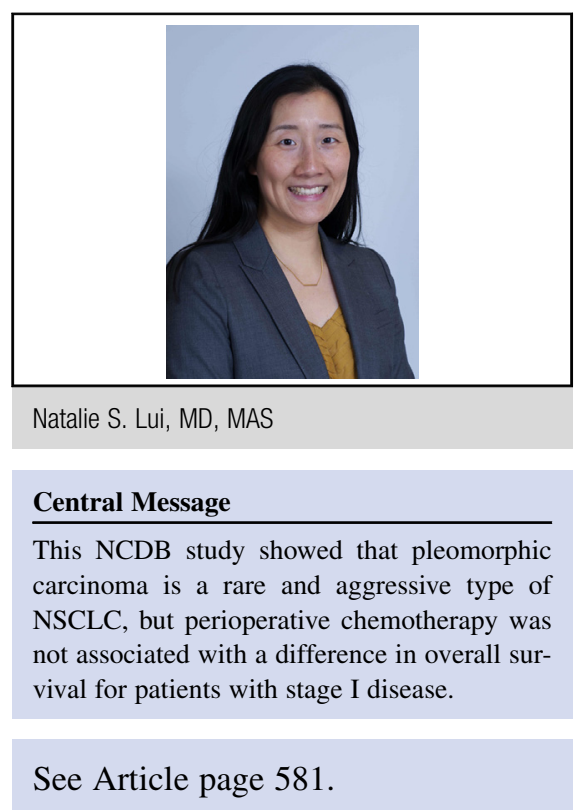

5-year overall survival compared with lobectomy (hazard ratio, $2.63 ; P<.001$ ).

The study has several limitations. First, the authors excluded tumor size in favor of $\mathrm{T}$ stage in their model. The seventh edition of the American Joint Committee on Cancer Cancer Staging Manual defined T2 as tumors 3 to $7 \mathrm{~cm}$ in size, which encompasses a wide range of risk. In this study, most patients who received chemotherapy had pT2 disease, and size $>4 \mathrm{~cm}$ is considered a high-risk factor in the National Comprehensive Cancer Network guidelines. Second, the NCDB does not include recurrence status, another important outcome when evaluating the efficacy of perioperative chemotherapy. Finally, the NCDB does not include results of molecular or programmed death-ligand 1 (PD-L1) testing, which is now recommended by the World Health Organization for pleomorphic carcinoma. ${ }^{2}$ Recent studies have shown several targetable mutations ${ }^{9}$ and high PD-L1 expression ${ }^{9,10}$ in pleomorphic carcinoma, which may change our approach to treatment.

The authors show that pleomorphic carcinoma is a rare and aggressive subtype of NSCLC, but there is no evidence to support treating patients with stage I disease with adjuvant chemotherapy outside of the guidelines. Surgeons 
should hesitate to perform sublobar resections for this subtype, and they should perform molecular and PD-L1 testing, just as they would other types of NSCLC.

\section{References}

1. Hendriksen BS, Hollenbeak CS, Reed MF, Taylor MD. Perioperative chemotherapy is not associated with improved survival in stage I pleomorphic lung cancer. J Thorac Cardiovasc Surg. 2019;158:581-91.e11.

2. Travis WD, Brambilla E, Nicholson AG, Yatabe Y, Austin JHM, Beasley MB, et al. The 2015 World Health Organization classification of lung tumors: impact of genetic, clinical and radiologic advances since the 2004 classification. $J$ Thorac Oncol. 2015;10:1243-60.

3. Chaft JE, Sima CS, Ginsberg MS, Huang J, Kris MG, Travis WD, et al. Clinical outcomes with perioperative chemotherapy in sarcomatoid carcinomas of the lung. J Thorac Oncol. 2012;7:1400-5.

4. Maneenil K, Xue Z, Liu M, Boland J, Wu F, Stoddard SM, et al. Sarcomatoid carcinoma of the lung: the Mayo Clinic experience in 127 patients. Clin Lung Cancer. 2018;19:e323-33.
5. Steuer CE, Behera M, Liu Y, Fu C, Gillespie TW, Saba NF, et al. Pulmonary sarcomatoid carcinoma: an analysis of the National Cancer Data Base. Clin Lung Cancer. 2017;18:286-92.

6. Rahouma M, Kamel M, Narula N, Nasar A, Harrison S, Lee B, et al. Pulmonary sarcomatoid carcinoma: an analysis of a rare cancer from the Surveillance, Epidemiology, and End Results database. Eur J Cardiothorac Surg. 2018;53: 828-34.

7. Boffa DJ, Rosen JE, Mallin K, Loomis A, Gay G, Palis B, et al. Using the National Cancer Database for outcomes research: a review. JAMA Oncol. 2017;3:1722-8.

8. National Comprehensive Cancer Network. Non-small cell lung cancer. https:// www.nccn.org/professionals/physician_gls/pdf/nscl.pdf. Accessed June 3, 2019

9. Kim S, Kim MY, Koh J, Go H, Lee DS, Jeon YK, et al. Programmed deathligand 1 and 2 are highly expressed in pleomorphic carcinomas of the lung: comparison of sarcomatous and carcinomatous areas. Eur J Cancer. 2015;51: 2698-707.

10. Schrock AB, Li SD, Frampton GM, Suh J, Braun E, Mehra R, et al. Pulmonary sarcomatoid carcinomas commonly harbor either potentially targetable genomic alterations or high tumor mutational burden as observed by comprehensive genomic profiling. J Thorac Oncol. 2017;12:932-42. 